\title{
Continuous Internal Evaluation:In a True Sense
}

\author{
B. B. Kotturshettar ${ }^{1}$, B. S. Kakol ${ }^{2}$, S. V. Khandal ${ }^{3}$ \\ ${ }^{1}$ Mechanical Department, BVBCET, Hubli-580031 \\ ${ }^{2}$ IPE department, BVBCET, Hubli-580031 \\ ${ }^{3}$ IPE department, BVBCET, Hubli-580031 \\ ${ }^{1}$ bbkshettar@bvb.edu \\ ${ }^{2}$ bskakol@bvb.edu \\ ${ }^{3}$ khandal@bvb.edu
}

\begin{abstract}
It has been experienced that an event based evaluation system always fails to evaluate the real learning of a student, as it emphasizes on memory based preparation and fails to provide the information on regularity in learning. Further, it is needed to engage students who are less oriented academically in learning and assessed in quick successions so that they are not burdened of preparing too much for the examination that are conducted after a long gap. Hence, it is always advisable to spread the evaluation evenly to entire span of the learning period. In the education system there were some efforts to reduce the period in between the evaluation events and it is successfully reduced to 6 weeks in a semester as of today. Still this period is not providing the continuity in the evaluation as this period also is considerably large. The paper proposes, weekly test as an effevtive tool to reduce the gap between Continuous Internal Evaluations (CIE) and this performance is considered as major component of overall CIE for theory courses. The paper provides the performance improvements in CIE of students in various courses and proves to be a better assessment process.
\end{abstract}

Keywords: Weekly test, CIE, Standard Deviation, assessment, Feedback

\author{
B. S. Kakol \\ IPE department, BVBCET, Hubli-580031 \\ bskakol@bvb.edu
}

\section{Introduction}

Provision of quality education has become indispensible for educational institutes all over the globe. Quality education requires an effective teaching and learning environment both inside and outside the classrooms. To create such an environment, is a challenging task which necessitates careful planning in collaboration with all the stakeholders. An effective learning environment motivates and stimulates student's learning process.

Inside the classroom, this can beachieved by capturing student's attention, transferring the subject knowledge, maintaining student's interest and usingclassroom assessments to monitor, measure and improve learning. All this can be achieved with active participation of students in their learning process and effective interaction between student and teacher. This demands integration of new learning-centric strategies with conventional classroom teaching. This educational transformation needs significant changes in the educational institutes at organizational level with learning at the center of all policies, plans, rules, decisions and at the classroom level with students at the center of all teaching and assessment activities.It is a continuous process rather than an event, built into the total teaching-learning process and spread over the entire span of academic session. It means regularity of assessment, frequency of unit testing, diagnosis of learning gaps, use of corrective measures, retesting and feedback of evidence to teachers and students for their self evaluation[1]. Assessment is used to monitor and measure learning after the teaching. An event based evaluation system always fails to evaluate the real learning of a student as it emphasizes on the memory based preparation and failed to provide the information on regularity in learning. Hence, it is always advisable to spread the evaluation evenly to entire span of the learning period[2]. 
Evaluation or assessment of student learning is usually done using the quizzes, homework, assignments, projects, case studies etc. The main drawback of this approach is that it is passive because it lacks student's active participation and engagement. These approaches will not assure of learning as few of them are evaluated in a group and in few cases it is malfunction. This problem becomes even worse for large class size with students of mixed ability. Hence regularly scheduled written examinations and assessments provide a true measure of the student learning. The history in engineering education reveals that, the policy makers tried to reduce the gap between evaluations constantly. In this regard they provided different schemes as shown in Table 1. The existing system has been identified with a few gaps in continuous assessment of a student. They are enumerated below.

Table.1: Different Schemes of Curriculum

\begin{tabular}{|l|l|l|l|}
\hline Sl. No. & Scheme & Duration & $\begin{array}{l}\text { Gap between } \\
\text { successive } \\
\text { evaluations }\end{array}$ \\
\hline 1 & Year & 52 weeks & 52 weeks \\
\hline 2 & Semester & 16 weeks & 6 weeks \\
\hline 3 & Trimester & 9 weeks & 4 weeks \\
\hline
\end{tabular}

- The student does not revise the discussed course content regularly.

- The last minute preparations for the internal examinations may lead to stress and students may not perform effectively.

- The parents express concern about the health issues due to overnight studies during examinations.

- The increase in tendency to apply for make-up examinations and course withdrawals.

The objective of this paper is to bridge the gaps identified in the present system by adopting a strategy of conducting weekly tests. This activity is carried out in a few identified core courses for fourth and sixth semester students of Industrial and Production Engineering.

The paper demonstrates:

- Effect of weekly tests in CIE performance

- Impact of the weekly tests on written presentation skills.

\section{The Effective Teaching Learning Framework}

The main idea of the frame work is that, effective teaching and learning techniques lead to student satisfaction and motivation to learn, when properly supported by a positive learning environment. The proposed framework consists of four main components: a) Strategies: Use of different student-centered techniques to support and enhance learning.

b) Roles: Assigning roles and responsibilities to all the stakeholders to ensure their active participation and collaboration.

c) Assessment: Assessment and evaluation methods to measure, monitor and promote learning.

d) Environment: Effective learning environment both inside and outside the classroom.

\section{A. Learning Assessments.}

In the learning process, assessments of and for learning are both important [3]. The assessment of learning monitors learning and identifies achievement. The assessment for learning promotes learning by helping students learn more. It uses the classroom assessment process and the information about student achievement to enhance student learning. Teaching and learning assessments can be divided into following three categories:

1) Diagnostic Assessment:It is usually done before the teaching in actual course content. It is used to check students' previous knowledge and skill levels. Diagnostic assessments help course instructor to plan the lecture to address different learning requirements of students.

2) Formative Assessment:It is done during the teaching. It is an ongoing assessment to give instant feedback to teachers and students. This information can effectively be utilized for guiding teaching to improve learning. Formative assessment methods include surprise quizzes, oral questioning, teacher observations and student reviews.

3) Summative Assessment:It is done at the end of semester, when the complete course is discussed. It sums up what students have learnt. These assessments areevaluative, and teachersusually summarizeand report assessment results as agrade.Familiar examples of summativeassessment include assignments, class tests or quizzes, performance tasks, final exams, course projects and work portfolios [4].

\section{Proposed CIE Through Weekly Test}

Assessment is a measure of the learning of a student. The following sub sections demonstrate the methodology adopted to carry out this strategy, action plan for the event, challenges addressed and its effectiveness.

\section{A. Methodology}

In one of the department meetings, it was resolved to conduct weekly tests for identified core courses of each $4^{\text {th }}$ and $6^{\text {th }}$ semesters in Industrial and Production Engineering discipline. The weightage assigned for this activity is 20 marks out of 50 in CIE. After a rigorous discussion, it was resolved to have five tests for every course of 25 marks 
each. Out of these five tests, best four would be considered for final evaluation as there was no make-up test for these weekly tests. This score would be reduced to 20 marks. The question paper carries five questions of 5 marks each without any options. The institution level calendar of events was considered in scheduling the weekly tests. Out of five tests, two were scheduled before minor I, and two before minor II and one after minor II. The last one would cater to the content covered after minor II exam, as there was no provision for evaluating this section in the regular pattern of minor examination.

\section{B. Challenges addressed.}

This section discusses about the challenges faced and the remedies for the same.

1) Time slots: It was very difficult to schedule five tests per course for seven courses. Hence on every Monday, first two hours were dedicated for these tests so that the weekends can be utilized for better purpose. This will ensure that the students need not miss their classes for preparations.

2)Evaluation: The question papers, detailed scheme and solutions are prepared by the course instructor. It was slightly over burdening for them to evaluate, five test papers along with two minor examinations. Hence the support was taken from the M. Tech students serving as teaching assistants in the department to conduct and evaluate these tests.

\section{Effectiveness of the proposed approach}

Effectiveness of the proposed approach is measured in three ways. First one is through the results obtained in academic performance; the second is through students' participation and third is through intermittent grades.

1) Improved academic performance:The attainment in performance of the student is shown in the Figure 1. This demonstrates the CIE improvement in the four courses. The Figure 2 shows the improved Semester End Examination (SEE) performance for the academic years for the respective courses. The Figure 3 and Figure 4 are the plots of standard deviation versus the various courses. These graphs indicate that, the deviation is reduced marginally in few courses. The syllabus of all the selected courses was unchanged from the previous year and same faculty engaged the respective courses.

2) Student participation:For the successful implementation of the proposed approach, it is not only enough to have a dedicated faculty, but also the students' active participation and enthusiasm matters. The data in Table 2 provides the details about their participation. The participation was found satisfactory in both the semesters. This has motivated the faculty to further continue with such practices in future.
This helps in further reforming the curriculum contents, mode of delivery and assessment.

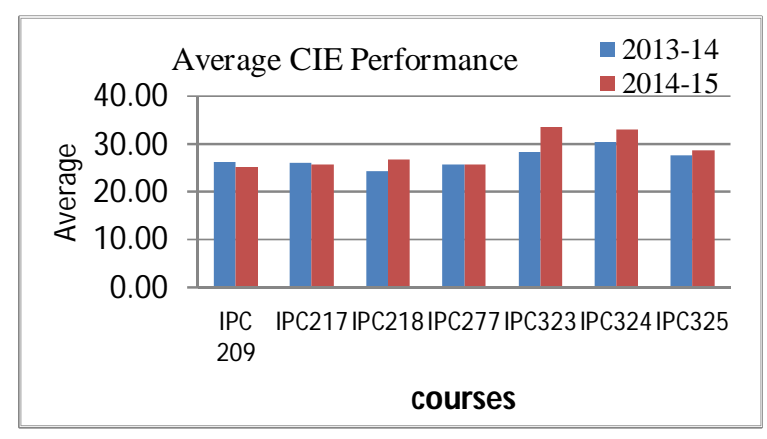

Fig.1: Performance of average CIE

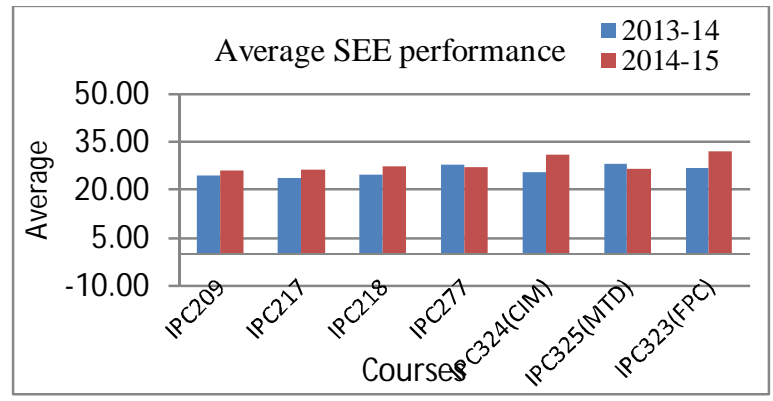

Fig.2: Average SEE Performance

Table.2: Student Participation

\begin{tabular}{|l|l|l|l|}
\hline Sem & $\begin{array}{l}\text { \% of } \\
\text { students } \\
\text { attending } \\
\text { all tests }\end{array}$ & $\begin{array}{l}\text { \% of students } \\
\text { attending } \\
\text { tests } \\
\text { out of 5 }\end{array}$ & $\begin{array}{l}\text { Total \% } \\
\text { Of students } \\
\text { Meeting min. } \\
\text { criteria }\end{array}$ \\
\hline $4^{\text {th }}$ & 42.85 & 28.57 & 71.42 \\
\hline $6^{\text {th }}$ & 72.05 & 22.05 & 94.10 \\
\hline
\end{tabular}

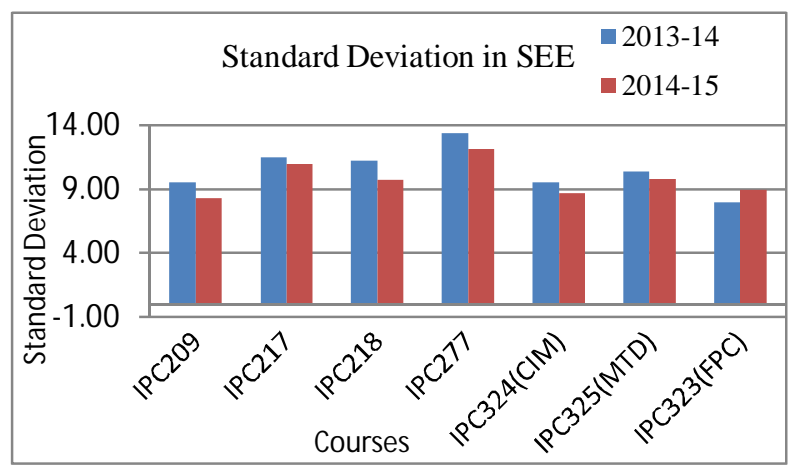

Fig.3: Influence of activity on Minor exams 
Table 3: Make Up Examination Applications for Minor1 and Minor 2

\begin{tabular}{|l|l|l|l|l|l|l|l|l|}
\hline Year & IPC209 & IPC217 & IPC218 & IPC277 & IPC323 & IPC324 & IPC325 & Total \\
\hline $2013-14$ & $8+1$ & $9+3$ & $14+1$ & $10+2$ & $5+3$ & $4+2$ & $3+4$ & 69 \\
\hline $2014-15$ & $4+0$ & $3+1$ & $4+1$ & $3+0$ & $6+1$ & $6+0$ & $5+4$ & 38 \\
\hline
\end{tabular}

Table.4: Statistics for $\mathrm{W}$ grade in SEE

\begin{tabular}{|l|l|l|l|l|l|l|l|l|}
\hline Year & IPC209 & IPC217 & IPC218 & IPC277 & IPC323 & IPC324 & IPC325 & Total \\
\hline $2013-14$ & 1 & 2 & 4 & 0 & 1 & 2 & 5 & $\mathbf{1 5}$ \\
\hline $2014-15$ & 0 & 2 & 1 & 0 & 1 & 1 & 0 & $\mathbf{5}$ \\
\hline
\end{tabular}

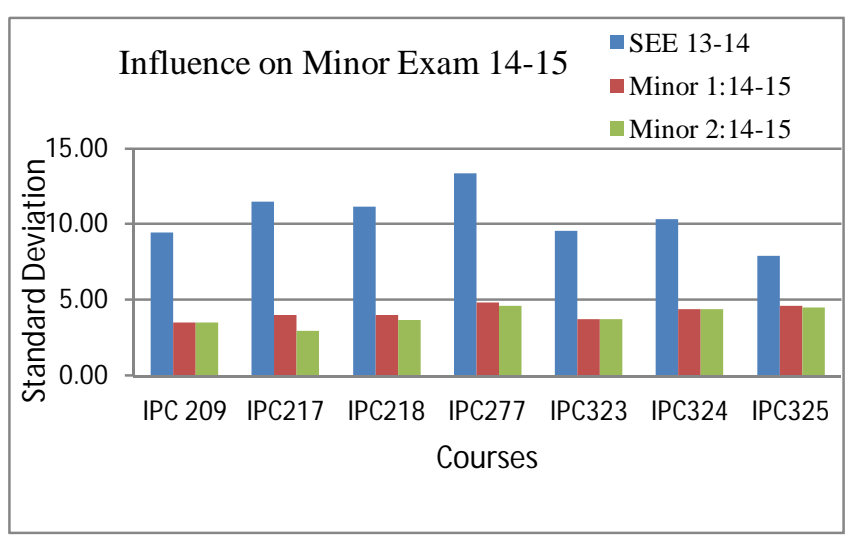

Fig.4: Variation of Standard Deviation in SEE

3. Intermittent grades:The number of students applying for the makeup examinations and withdrawal of the courses has reduced to a greater extent. The Table 3 shows the decreased number of the applications for the makeupexaminations. The Table 4 shows the reduction in the number of students withdrawing the courses during SEE. These statistics emphasize that, the confidence level of the students has boosted and are ready to face the examinations.

4.Students' feedback:On an average 50\% students opine that the weekly test is a positive step towards enhancing their learning performance in courses and also preparation for SEE while about $25 \%$ students are neutral. Majority students feel that these tests help their learning irrespective of whether the course is mathematical or theoretical one.

\section{Conclusion}

The paper demonstrates the influence of continuous evaluation on the overall performance of the student. It facilitates the students who are less oriented academically to engage them in learning and are assessed in quick successions, so that they are not burdened of preparing too much for the examination that are conducted at a longer

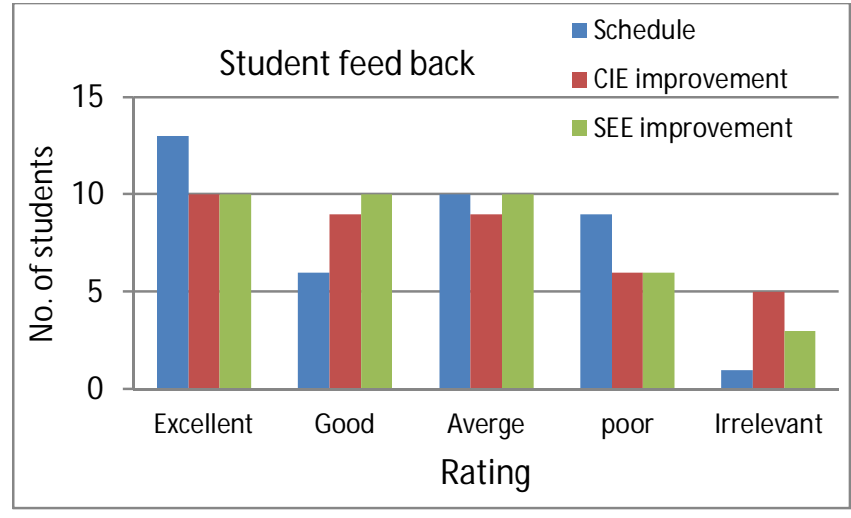

Fig.5: Students' feedback to measure the effectiveness.

gaps. It showed that, it is always advisable to spread the evaluation evenly to entire span of the learning period. The proposed weekly test turned out to be an effevtive technique to reduce the gaps between written evaluations and the performance is considered as major component of final CIE for courses.

\section{Acknowledgement}

The authors wish to thank the faculty of IPE department for cooperating to conduct this activity.

\section{References}

[1] Goutam Verma, 'Continuous and comprehensive evaluation", Scribd digital library

[2] Director of State Education, Research and training Bangalore, 'New dimensions in evaluation', position paper.

[3] Stiggins, R. J. (2002), 'Assessment crisis: The absence of assessment for learning', Phi Delta Kappa, 83(10), 758765.

[4] McTighe, J., \& O'Connor, K. (2009), 'Seven practices for effective learning. Kaleidoscope: Contemporary and Classic Readings in Education', 174. 